\title{
ANTECIPAÇÃO DOS EFEITOS DA TUTELA "EX OFFICIO" NOS CASOS DE ABUSO DO DIREITO DE DEFESA OU MANIFESTO ESCOPO PROTELATÓRIO DO RÉU
}

\author{
Adonis Reis de Medeiros Filho \\ IFRN - NIT, Bolsista Projeto Inovar para Consolidar, adonisrmf@ gmail.com.
}

\section{RESUMO}

O presente trabalho tem como intuito estudar o instituto da antecipação dos efeitos da tutela, especialmente a possibilidade de sua concessão "ex officio" nos casos de abuso do direito de defesa ou manifesto escopo protelatório do réu. De início analisando os requisitos legais da antecipação dos efeitos da tutela e, em seguida, será dado o enfoque na antecipação dos efeitos da tutela "ex officio" nos casos de abuso do direito de defesa ou manifesto escopo protelatório do réu, onde será esclarecido se o Magistrado pode ou não conceder tal medida "ex officio" como elemento punitivo nos casos de abuso do direito de defesa ou manifesto escopo protelatório do réu.

PALAVRAS-CHAVE: Processo Civil, Tutela Antecipada, Concessão Ex Officio.

\section{ANTICIPATING THE EFFECTS OF GUARDIANSHIP "EX OFFICIO" IN CASES OF ABUSE OF THE RIGHT OF DEFENSE OR MANIFEST SCOPE PROCRASTINATING OF THE DEFENDANT}

\begin{abstract}
This paper aims to study the institute of anticipating the effects of guardianship, especially the possibility of granting "ex officio" in cases of abuse of the right of defense or manifest scope procrastinating of the defendant. Starting analyzing the legal requirements of anticipating the effects of guardianship and then be given the focus on anticipating the effects of guardianship "ex officio" in cases of abuse of the right of defense or manifest scope procrastinating of the defendant, where it will be clear whether the magistrate can or not grant such measure "ex officio" as punitive element in cases of abuse of the right of defense or manifest scope procrastinating of the defendant.
\end{abstract}

KEYWORDS: Civil Procedure, Anticipating the Effects of Guardianship, Granting "Ex Officio". 


\section{ANTECIPAÇÃO DOS EFEITOS DA TUTELA "EX OFFICIO" NOS CASOS DE ABUSO DO DIREITO DE DEFESA OU MANIFESTO ESCOPO PROTELATÓRIO DO RÉU}

\section{INTRODUÇÃO}

O objetivo deste trabalho consiste na análise de um assunto bastante controvertido no ordenamento jurídico, qual seja a possibilidade do Magistrado conceder a antecipação de tutela "ex officio", ou seja, sem requerimento expresso da parte ou de seu advogado, especificamente nos casos de abuso do direito de defesa ou manifesto escopo protelatório do réu.

Apesar da concessão da antecipação dos efeitos da tutela "ex officio" ser bastante aceita e difundida por vários doutrinadores em determinados casos, não nos parece razoável a sua concessão nos casos específicos de abuso do direito de defesa ou manifesto escopo protelatório do réu.

Assim, a principal finalidade deste trabalho é demonstrar que tal medida no processo civil não deve ser concedida "ex officio", e que a não concessão não importará em prejuízo para nenhuma das partes, principalmente porque existem outras medidas previstas na legislação atinente para sancionar os referidos abusos.

Para tanto foram utilizados artigos científicos, busca em sites que abordam o tema, bem como livros doutrinários, a legislação referente na área direcionada para o Direito Processual Civil.

\section{CONCEITO E PREVISÃO LEGAL}

A Lei $\mathrm{n}^{\circ}$ 8.952, de 13.12.1994 inseriu algumas novidades no Código de Processo Civil, dentre elas alterou o artigo 273 introduzindo a tutela antecipada, que tem por objetivo a distribuição do ônus do tempo do processo, garantindo imediatamente o direito afirmado pela parte. $\mathrm{O}$ que, consequentemente, traz mais celeridade e efetividade ao resultado prático do processo (Bueno, 2009).

Para isso deverão estar presentes alguns requisitos, elencados pelo artigo 273 do CPC, quais sejam: a existência de prova inequívoca, verossimilhança das alegações e haja fundado receio de dano irreparável ou de difícil reparação ou fique caracterizado o abuso de direito de defesa ou o manifesto propósito protelatório do réu.

Apesar de o caput do artigo 273 dispor claramente que "O juiz poderá, a requerimento da parte, antecipar, total ou parcialmente, os efeitos da tutela pretendida no pedido inicial..." (grifos acrescidos), a doutrina vem debatendo bastante acerca da possibilidade de o juiz conceder antecipação de tutela de ofício caso verifique abuso de direito de defesa ou manifesto propósito protelatório do réu.

\section{POSSIBILIDADE X IMPOSSIBILIDADE}

Os defensores da possibilidade da concessão da antecipação dos efeitos da tutela de ofício procuram respaldo na aplicação análoga do artigo 797 do CPC, ou, na opinião de Daniel Mitidiero, tal concessão não violaria a regra da inércia da jurisdição, pois o juiz não estaria ultrapassando os limites do pedido, mas tão somente antecipando seus efeitos. 
Para Cassio Scarpinella Bueno, "Se o juiz, analisando o caso concreto, constata, diante de si, tudo que a lei reputa suficiente para a antecipação dos efeitos da tutela jurisdicional, à exceção do pedido, não será isso que o impedira de realizar o valor 'efetividade', máxime nos casos em que a situação fática envolver urgência da prestação da tutela jurisdicional”.

Há, também, quem defenda a medida de ofício como forma de punição para preservar a lealdade processual, visto que a litigância de má fé é um dos parâmetros para a antecipação dos efeitos da tutela neste caso, e pode ser decretada de ofício pelo juiz. Neste sentido Carlos Augusto de Assis e Benedito Pereira Filho.

Para os que defendem a impossibilidade da concessão da tutela antecipada de oficio, tal impossibilidade decorre da simples interpretação sistemática da lei processual, transgride a regra da congruência, adotado pelo CPC nos artigos 128 e 460 e ainda viola o princípio da inércia do Judiciário.

Este é o entendimento de Fredie Didier Jr.:

\begin{abstract}
"Não parece ser possível a concessão ex officio, ressalvadas as hipóteses expressamente previstas em lei, não só em razão de uma interpretação sistemática da legislação processual, que se estrutura na regra da congruência. A efetivação da tutela antecipada dá-se sob a responsabilidade objetiva do beneficiário da tutela, que deverá arcar com os prejuízos causados ao adversário, se for reformada a decisão. Assim, concedida ex officio, sem pedido da parte, quem arcaria com os prejuízos, se a decisão fosse revista? A parte que se beneficiou sem pedir a providência? É preciso que a parte requeira a concessão, exatamente porque, assim, conscientemente se coloca em uma situação em que assume o risco de ter de indenizar a outra parte, se restar vencida no processo."
\end{abstract}

\title{
CONCLUSÃO
}

Assim, a despeito dos argumentos apresentados com base na discussão doutrinária acerca da possibilidade de concessão de ofício da tutela antecipada nos casos de abuso de direito de defesa ou manifesto propósito protelatório do réu, nos filiamos à corrente que defende a impossibilidade da adoção de tal medida.

Primeiramente porque a finalidade real do artigo 273 do CPC é, conforme anteriormente disposto, a distribuição do ônus do tempo do processo, garantindo imediatamente o direito afirmado pela parte. Sendo a celeridade e a efetividade meras consequencias desta.

E em segundo lugar, o Código de Processo Civil já contém sanções previstas para os casos de abuso de direito de defesa ou manifesto propósito protelatório do réu, que o juiz poderá aplicar de ofício. São as regras dispostas nos artigos 16, 17 e 18, que por si só já deveriam garantir a ordem processual.

Todavia não se trata simplesmente da interpretação sistemática do CPC ou pelo fato do requerimento da parte estar previsto no caput do artigo 273. Estes entendimentos poderiam ser facilmente superados pela doutrina e jurisprudência.

Dada a devida vênia, o nosso entendimento é que problemática que abarca a referida questão se trata, mais precisamente, de quem será a responsabilidade objetiva de arcar com os danos causados ao demandado, caso a decisão seja reformada. 
Não nos parece correto que a parte beneficiaria da antecipação da tutela, que não requereu tal medida, portanto não assumiu o risco de uma possível indenização à parte contrária, seja penalizada de tal forma.

Ao Judiciário, ou ao juiz, também não poderá ser imputada tal responsabilidade. Portanto, não deverá o juiz conceder antecipação dos efeitos da tutela de ofício caso verifique abuso de direito de defesa ou manifesto propósito protelatório do réu.

\section{REFERÊNCIAS}

1. BUENO, Cassio Scarpinella. Tutela antecipada. Fonte: Curso sistematizado de Direito Processual Civil: tutela antecipada, tutela cautelar, procedimentos cautelares específicos. São Paulo: Saraiva, 2009, pp. 09-41. Material da $5^{\text {a }}$ aula da disciplina Fundamentos do Direito Processual Civil, ministrada no curso de Pós-Graduação Lato Sensu TeleVirtual em Direito Processual Civil -Anhanguera- Uniderp/IBDP/Rede LFG.

2. DIDIER JR., Fredie, OLIVEIRA, Rafael, BRAGA, Paula Sarno. Curso de Direito Processual Civil. Vol. 2. $5^{\text {a }}$ ed. Salvador: JusPODIVM, 2010.

3. SANTIAGO, Edna Ribeiro. Impossibilidade de concessão da tutela antecipada de ofício nos casos de abuso do direito de defesa ou manifesto intuito protelatório do réu. Jus Navigandi, Teresina, ano 15, n. 2553, 28 jun. 2010. Disponível em: <http://jus.uol.com.br/revista/texto/15100>. Acesso em: 12 nov. 2010.

4. SILVA, Igor Menelau Lins e. A tutela antecipada e a possibilidade da concessão "ex officio" no processo civil brasileiro. Jus Navigandi, Teresina, ano 14, n. 2160, 31 maio 2009. Disponível em: <http://jus.uol.com.br/revista/texto/12829>. Acesso em: 12 nov. 2010 .

5. MITIDIERO, Daniel Francisco. Comentários ao Código de Processo Civil. São Paulo: Memória Jurídica, 2006, t.3.

6. PEREIRA FILHO, Benedito. Tutela antecipada: concessão de ofício? Revista da Ajuris, Porto Alegre/RS, ano XXXI, no. 95, p. 37/53, setembro de 2004.

7. ASSIS, Carlos Augusto de. A antecipação da tutela. São Paulo: Malheiros Ed., 2001.

8. $\quad$ DINAMARCO, Cândido Rangel. Fundamentos do Processo Civil Moderno - v. II. 5 ed. São Paulo: Malheiros Editores, 2002.

9. LOPES, João Batista. Tutela antecipada no processo civil brasileiro. 3 ed. São Paulo: Editora Revista dos Tribunais, 2007. 